\title{
Two Types of Change-of-State Attributes in English
}

\author{
Beatriz Rodríguez Arrizabalaga \\ University of Huelva \\ arrizaba@uhu.es
}

\begin{abstract}
Contrary to the common belief that all attributes denoting a change of state belong to one and the same uniform class, we strongly defend in the present paper the existence of two distinct syntactico-semantic kinds of change of state attributes in the English language: on the one hand, those that complement the aspectual variants of the semantically vacuous copula be; and, on the other hand, those that combine with lexically autonomous verbs and are, therefore, optional for the grammaticality of the construction. Due to the markedly different behaviour they exhibit, we are going to distinguish both classes of attributes from a terminological point of view: we will call the members of the former group 'change of state attributes', strictly speaking, and those of the latter type, resultative attributes. To prove our hypothesis, we are going to base our study mainly on the nature of the verbal constituent that surfaces in the attibutive structure and, as a consequence, on the syntactic and semantic relation it maintains with the attribute under discussion.
\end{abstract}

1. The attributive phenomenon in the linguistic tradition. A brief survey of its evolution and development

The linguistic phenomenon of attribution originates within the theoretical framework of Traditional Grammar as the diametrically opposed phenomenon to the one commonly known as predication. Whereas the former includes predicate nominal sentences that denote qualities or states ${ }^{1},(1-2)$, the latter embraces verbal predicate clauses that, on the contrary, describe processes, (3-4): 
(1) Her hair felt rough and unpleasant to the touch. ${ }^{2}(M T: 125)$

(2) My voice was getting high and thin. (WSS: 93)

(3) He spoke into his ears. (PPS: 397)

(4) He returned to the bed. (PPS: 400)

Being confined to the small and restricted group of copulative verbs, attribution is considered to be in this particular theoretical framework a grammatical phenomenon with very clear and easily differentiated boundaries.

Due to the dogmatic character acquired by the dichotomous pairs qualitiesstates/processes and nominal/verbal predicates, this first concept of attribution remains as an unanswerable issue until linguists of Hernández Alonso's stature (1971) categorically demonstrate that such a sharp distinction between attribution and predication can no longer be maintained on either syntactic or semantic grounds. Among the many reasons put forward by this author, the existence of many clauses that, like (5)-(6), combine in their predicate sintactico-semantic features of the two grammatical phenomena under discussion seems to be the most convincing one: ${ }^{3}$

(5) He walked barefoot into the kitchen. (RL:239)

(6) The workshop window flung open. (MSW: 95)

Instead of viewing attribution as an anomalous linguistic phenomenon, exclusive only to a reduced class of verbs, Hernandez Alonso's paper presents such a grammatical phenomenon as highly productive and fully integrated in the language. He explains this fact with the following words:

[...] apreciamos que el grupo de las oraciones atributivas no debe ser interpretado ni tratado independientemente como un extraño predicado de dos verbos "fantasmas" opuestos a todos los demás. Son unas construcciones desgajadas de otras predicativas intransitivas con una notable gramaticalización y gran extensión de uso por su amplitud semántica ${ }^{4}$ (Hernández Alonso, 1971: 339).

The above-mentioned study constitutes, therefore, a turning point in the research of such a linguistic field. From this moment on, the attributive phenomenon begins to receive the deserved linguistic treatment which it has been deprived of for quite a long time, becoming, thus, the central subject matter of a considerable number of functional works in the last two decades (cf. Martínez Vázquez, 1991; Gonzálvez García, 1996; 1998 in the English linguistic tradition and Gutiérrez Ordóñez, 1986; Porroche Ballesteros, 1990 and Penadés Martínez, 1994, among others, in the Spanish one). ${ }^{5}$ These new and recent studies on attribution take Hernández Alonso's proposal as a starting point and, consequently, defend, in sharp contrast with what was believed in Traditional Grammar, that it is a linguistic phenomenon whose extension is quite difficult to delimit with precision and accuracy, owing mainly to the great variety of syntactic, lexico-semantic and pragmatic factors that such a phenomenon involves (cf. Gutiérrez Ordóñez, 1986: 20; Martínez 
Vázquez, 1991: 20). In Martínez Vázquez's words (1991: 20), for instance, this same idea is expressed as follows:

[...] no podemos delimitar las estructuras atributivas mediante la clasificación de uno de sus elementos a priori, sino que hay que considerar la atribución como un fenómeno que implica tres elementos en una relación de interdependencia.

In the present paper we follow this broad and fairly recent concept of attribution. As a consequence, apart from the canonical attributive pattern of Traditional Grammar illustrated in (7-8) and composed of a 'theme' $(T),{ }^{6}$ a copulative verb $(V)$ and an attribute $\left(A_{t r}\right)$, we also regard as 'attributive' those constructions, like (9-10), which join into a single syntactic structure two different relations of predication: a primary verbal predication of quite varied syntactico-semantic nature and a secondary or adjacent attributive one:

(7) The cheese tastes sour. (RL: 182)

(8) And then you turned scarlet. (MSW: 663)

$$
T \text { V } A_{t r}
$$

(9a) Polly watched him open-mouthed. (MSW: 222)

$\mathrm{T} \quad \mathrm{A}_{\mathrm{tr}}$

(10a) My throat was swelling shut. (MSW: 213)
$\mathrm{T}$
$\mathrm{A}_{\mathrm{tr}}$

As the previous examples show, the attributive clauses with two different relations of predication formally differ from the traditional ones in not having the copulative verb overtly indicated at the surface level of expression. This does not mean, however, that the copulative verbal constituent is entirely missing from this type of attributive clause. As the following paraphrases illustrate, it does exist, though implicitly, at the semantic level of interpretation:

(9b) When Polly watched him, Polly was open-mouthed

(10b) My throat was becoming shut, because it was swelling.

\section{Semantic classification of attributive patterns. The change of state parameter}

The semantic concept of 'change of state' is extremely important when investigating the linguistic phenomenon of attribution. In point of fact, all the semantic classifications established within the attributive realm base themselves on this specific parameter. The most immediate result of such classifications leads to the division of attributive patterns into two wide semantic groups: on the one hand, those describing a change of state that modifies either the external or internal nature of the logical subject of the attribute, like (11-12); and on the other hand, those attributive structures that denote something completely different: 
whereas (13) expresses, for instance, the permanence of the nominal entity $I$ in the state of 'silence' referred to by the attribute, the sentence in (14) indicates that the theme of the attribution, the voice, has two particular properties, being queer and metallic, that are physically perceived by the sense organ of hearing:

(11) Aunt Margaret grew even thinner and more spectral. (MT: 134)

(12) The butter had gone rancid. (MSW: 579)

(13) I remained silent at his side. (FP: 103)

(14) My voice sounded queer, metallic. (MSW: 608)

If we observe these four examples carefully, we realise that the semantic classification previously observed depends directly on the lexical meaning of their copulative verbs, which, though in some way grammaticalised, still retain in their attributive use some part of their original meaning as either transitive or intransitive verbs. It is, therefore, a semantic classification that follows the spirit of the earliest ones carried out by Poustma (1926-29) and Curme (1931) within the theoretical framework of Traditional Grammar. Below we present how these two linguists grouped together the different copulative verbs:

a) Verbs that, like to be, express a state and verbs of sensory perception such as feel, taste and smell.

b) Verbs that indicate the permanence of a nominal entity $\mathrm{X}$ in an state $\mathrm{Y}$ : remain, continue.

c) Verbs, like become, that imply the entrance in a new state.

Apart from tracing its origin back to Traditional Grammar, the semantic classification under discussion is considered to be one of the most significant goals achieved by this, above all semantic, linguistic theory. In point of fact, it has extended beyond its frontiers, entering the domains of some recent approaches to the study of language. Downing and Locke (1992: 99) and Givón (1993: 101; 103), for instance, are good examples in this regard, since they both keep the distinction between copulative verbs of being and copulative verbs of becoming intact in their highly influential functional studies on English grammar.

But what is really significant for our purposes in this study is that, in spite of lacking an overt copulative verb at the surface level of expression, the attributive structures with two different relations of predication can be subjected to a semantic classification similar to the one previously illustrated. As can be seen in (15-18), it is once more the semantic parameter of 'change of state' that is crucially involved in determining the lexico-semantic properties of the following clauses. Therefore, whereas the verbs in (15-16) do not imply any type of mutation in the states of their grammatical subjects $I$ and she, those in (17-18) do transform the original nature of the entities they are predicated of: in (17) the door becomes tied as a result of the verbal action denoted by tie and in (18) the hair is said to acquire a new and different colour: 
(15) I arrived exceedingly wet and much incommoded by the surge. $(C: 20)$

(16) She wore a black waist unbuttoned. (MSW: 51)

(17) I tied the door shut. (MSW: 187)

(18) She dyed her hair a warm chesnut. (RL:270)

Due to this obvious semantic opposition, linguists such as Jespersen (1909-49: 355) distinguish very early in the twentieth century two distinct classes of attributes, which he calls 'predicatives of being' and 'predicatives of becoming'. Later on, Halliday (1967: 63) names them depictive and resultative, respectively; and more recently, Greenbaum and Quirk (1990:210) refer to them as current and resulting attributes. It has to be remarked at this point, however, that Halliday's terminology is wider in scope than the ones provided by Jespersen and Greenbaum and Quirk. Apart from the attributes that complement the traditional and limited class of copulative verbs, the Hallidayan attributive dichotomy 'depictive/resultative' also applies to those attributes that constitute the secondary lexical predicates of a sentence. That is, the pairs of attributes happy-full and friend-dry in the following examples are considered to belong, according to Halliday, to the same semantic class: the former are classified in his study as depictive attributes and the latter, in turn, as resultatives:

(19) She was happy. (Halliday, 1967: 63)

(20) He dropped the tray full.

(21) They became friends.

(22) The cakes burn dry.

A somewhat similar classification is carried out by Martínez Vázquez (1991: 130) within the group of attributive clauses describing a change of state. It has to be pointed out, nevertheless, that the linguist, though including as Halliday does all the attributes in (23-26) in the class of 'resultatives', is fully aware of the fact that they complement verbal constituents with a totally distinct syntactico-semantic status. Hence, Martínez Vázquez classifies the examples in (23-24) as resultative attributive structures with a copulative verb and those in (25-26) as resultative attributive clauses with a non-copulative verb:

(23) He grew pale. (Martínez Vázquez, 1991: 130)

(24) I proved it wrong.

(25) He blushed crimson.

(26) They scared him silly.

Leaving aside the terminological and scope distinctions commented above, all the aforementioned linguists agree in explaining in temporal terms the main difference that exists between the two semantic types of attributes that they identify. That is, whereas resultative attributes are said to be the direct consequence of the action denoted by the verb with which they combine, current or depictive attributes exist totally independent of the 
verbal process. As a result, the former are temporally posterior to the verbal action and the latter, in turn, maintain either a simultaneous or anterior temporal relationship with the verbal head of their clause.

\subsection{Two classes of change of state attributes}

Contrary to the common belief that all attributes denoting a change of state pertain to only one and the same uniform class, we strongly defend in the present paper the existence of two distinct syntactico-semantic kinds of change of state attributes. To prove our bypothesis, we are going to focus mainly on the different behaviour exhibited by the members integrating both classes of attributes and on the syntactico-semantic nature of the verbal constituent that surfaces in the attibutive constructions at issue.

As regards the widespread assumption in the literature that all change of state attributes maintain a posterior temporal relation to the action denoted by the verbal constituent of their clauses, we deem it necessary to make some refinements. To start with, we firmly believe that this previous assertion is solely valid in the environment of attribution as secondary predication. That is, only those attributes that are the secondary lexical heads of an attributive construction pass the temporal subordination test. According to this syntactic test, the attribute in question appears in the main clause as the complement of the copulative verb become, and the verbal action causing such a change of state is, in turn, subordinated to it by means of a conjunction expressing, like after in the examples that follow, a posterior temporal relationship:

(27) I tore the letter open. (MSW: 135) $\rightarrow$

The letter became open after being torn.

(28) The cow licked her face clean. (MSW: 4) $\rightarrow$

The cow's face became clean after being licked (by the cow).

Nevertheless, if the attribute complements any of the aspectual variants of the semantically vague copula $b e$ that denote a change of state, the aforementioned test leads to ungrammatical results. We can conclude, therefore, that these change of state attributes do not maintain at all such a temporal relationship with the verbal constituent of their patterns:

(29) I became, necessarily, 'a great butler'. $(R D: 70) \rightarrow$

*I became a great butler after becoming.

(30) In spring the land turns emerald. (MSW:107) $\rightarrow$

*In spring the land becomes emerald after turning.

The contrast we notice between both classes of attributes is merely one of the many consequences deriving from the very distinct syntactico-semantic nature of the verb with which they combine. Whereas the verbal constituent of those attributive structures with two 
relations of predication is a lexical verb with syntactic autonomy, the aspectual copulative variants describing a change of state are syntactically, as well as semantically, dependent on the attributive element. Hence, the syntactic optionality of the attribute in the first type of constructions, (31b-32b), and its obligatoriness in the second one, (33b-34b):

(31a) The walls were painted a sickly yellow. (MSW: 579)

(31b) The walls were painted.

(32a) He knocked her unconscious. (MSW: 569)

(32b) He knocked her.

(33a) That piece of orange cheese had gone hard and cracked. (RL: 204)

(33b) *That piece of orange cheese had gone.

(34a) They fell into a mood of disrepair. (MSW: 130)

(34b) \#They fell. ${ }^{7}$

Being lexically autonomous verbs, the meaning of the verbal constituents of the bipredicative attributive sentences allows the hearer to guess, in most of the cases, which is the resultant state caused by the change of state process it implies. If we analyse the verbs break and wash from a lexico-semantic viewpoint, we can surely conclude that the actions they denote presuppose the acquisition of a specific new state: that of being 'broken' in (35) and that of boing "clear? "in $(35$.

(35) The fox broke the egss open. (ASW: 363)

(36) So she began vo un, io the stream, to wash herself ciean. (I: 84)

In contrast, the semantic weakness and vagueness that characterise the copulative verbs convert them into mere carriers of aspectual nuances. Since they forcefully require the explicit presence of an attribute to form a syntactically and semantically acceptable unity, the change of state process is not indicated in these cases by the verbal constituent alone, but by its conjunction with the attribute for which it subcategorizes. Contrary to what happens in (35-36), the verbs turn and go in the following examples do not specify, in isolation, the changes of states that are undergone by the themes of the attributive relationship the air and the butter, respectively:

(37) The air has turned bitter. $(C: 10)$

(38) The butter had gone rancid. (MSW: 579)

Since the verbs and attributes of these structures constitute a syntactico-semantic unity, indivisible even in temporal terms, it seems absurd to look for a temporal sequencing between both clausal constituents.

Taking into consideration this contrastive verbal behaviour, we can explain some other facts that differentiate both classes of change of state attributive clauses. Whereas the attribute complementing a copulative verb is always interpreted as the new property that the 
theme of the attributive relationship acquires, the syntactically optional attribute joined to the lexical verb of a bipredicative attributive sentence can also be understood as implying some prior or simultaneous property to the verbal action. In (39), for example, the states of 'virginity' and 'mysticism' described by the coordinated attribute $a$ virgin and a mystic clearly precede the change of state process implied by the verb die:

(39) $[\ldots]$ the young girl who dies a virgin and a mystic. (FP: 119)

This difference proves, once again, that the interdependent relation existing between copulative verb and attribute is more solid than the one linking a lexical transitive or intransitive verb and its optional attribute. The frontier between these last two elements is, in turn, quite easily identifiable.

All the contrasts noted above lead us to distinguish two classes of change of state attributes: in one class we group together those attributes that complement the aspectual variants of $b e$, and in the other we include those attributes that combine with lexical verbs. We call the former kind of attributes 'change of sate attributes', strictly speaking, and the latter, in turn, 'resultative attributes'.

Once the basic behaviour of both kinds of attributes is presented, we consider it necessary to make some commentaries regarding resultative attributes and their syntactic environment. It the first place, it is necessary to remark, as Demonte $(1991: 160)$ does, that the resultative attribute does not simply express a change of state that is temporally posterior to the verbal action, but the final state derived from it:

Conviene no perder de vista asimismo que los resultativos se refieren siempre a estados finales, a los que acontecen cuando se ha completado una determinada acción (Demonte, 1991: 160).

And secondly, that the resultative attribute complements a verb of action (cf. Simpson, 1983: 143; Rapoport, 1993: 164; Levin, 1993: 101). That is, the resultative attribute always combines with dynamic verbs. Levin (1993: 101), for instance, expresses this idea with the words that follow:

A resultative phrase is an XP which describes the state achieved by the referent of the NP it is predicated of as a result of the action named by the verb.

The correlation result $\rightarrow$ action is not exclusive, however, to attributive resultative constructions. As Kac (1972: 123) explains, it is a correlation underlying all types of resultative predicates: "For result predicates, assertion of a result presupposes an action."

The verbal component of the unipredicative attributive sentences indicates, on the contrary, a process. To demonstrate such a verbal distinction, we make use of the syntactic tests provided by Chafe $(1970: 100)$. That is, we employ what happened to...? to question those clauses with verbs that denote a process, and What did someone do...? to ask about those ones that involve any type of activity: 
(40) His rounded boneless limb grew strong. $(R L: 3) \rightarrow$

What happened to his rounded boneless limbs?

*What did his rounded boneless limbs do?

(41) He polished them clean with his handkerchief. (MT: 81-82) $\rightarrow$

*What happened to him?

What did he do?

Since they systematically denote a process, all the aspectual verbs of the unipredicative attributive clauses are characterised as being inherently dynamic verbs that imply change: become, grow, turn, get, go, come, run, etc. In the constructions with two predicative relations, nevertheless, the change of state nuance does not always come from the semantic meaning of the verbal constituent. The verb of these attributive structures, as (42-43) show, does not have to express a change of state, since in these cases the semantic notion of mutation comes from the conjunction of the verbal constituent with the resultative attribute:

(42) He drank it dry. (Garrudo, 1991: 129)

(43) I shouted myself hoarse. (Garrudo, 1996: 615)

Apart from distinguishing two classes of change of state attributes, all the facts analised throughout this work lead us to differentiate two semantic concepts: that of mutation and that of result. Whereas we believe that the semantic notion of change of state is inherent to the verbal category, the feature [+ resultative] seems to be a property of the attributive element. It has to be taken into consideration, furthermore, that whereas a result always implies a change of state, the same relation in the contrary direction does not systematically hold: a change of state does not always imply a result.

A very similar opinion is defended by Riviére (1981: 165) in his study on the English resultative constructions when excluding from such a syntactic pattern the appearance of the copulative verbs become, get, grow, turn, etc. for inherently denoting a change of state. He explains it as follows:

Les verbes de cette catégorie ${ }^{8}[\ldots]$ son écartés de l'etude parce que je considère que ce qui fait l'intérêt des schémas résultatifs est justement que les verbes qui s'y insèrent n'expriment pas par eux mêmes un changement d'état. [...] En fait, l'existence (universelle) de tels verbes est totalement indépendante de l'existence de schémas résultatifs.

\section{Conclusions}

In the present paper we have demonstrated the existence in the English language of two highly different syntactico-semantic classes of change of state attributes: one class groups together those attributes that complement the aspectual variants of the semantically neuter copula be that describe a change of state (become, grow, turn, go, get, come, etc.), and the 
other one embraces, in turn, those attributes that optionally figure in the argument structure of lexical verbs such as break, paint, wash and many others. We have called the members of the former class simply 'change of state attributes' and those belonging to the latter group, 'resultative attributes'. As has been shown throughout this study, the previous division is mainly motivated by the distinct syntactico-semantic behaviour displayed by the verbal constituent of both types of attributive clauses and, as a consequence, by the particular relationship it maintains with its change of state attributes. What really underlies such a binary distinction is, nevertheless, a recent and wide conception of attribution which, apart from the canonical copulative clauses of Traditional Grammar, also includes in its scope those structures that combine in only one syntactic pattern two distinct relations of predication: the first one being verbal in nature and the second one, in contrast, attributive.

\section{Notes}

1. Although qualities as well as states denote properties in the extralinguistic world, these two terms can not be considered synonyms. As Jackson (1990: 10) explains, the difference existing between them lies in the temporal duration of the properties they refer to: "A 'quality' is a more or less permanent characteristic of someone or something, while a 'state' is a less permanent type of situation".

2. The whole corpus of examples used throughout this paper comes from a selection of contemporary novels written in English. To make the comprehension of the text easier, we indicate with brackets the source of each individual instance by means of an abbreviation that stands for the title of the novel where such an example has been found:

-. $(C) \rightarrow \quad$ Phillips, C (1991): Cambridge. London: Picador.

-. $(F P) \rightarrow \quad$ Barnes, J (1984): Flaubert's Parrot. London: Picador.

-. $(I) \rightarrow \quad$ Warner, M (1992): Indigo. London: Vintage.

-. $(M S W) \rightarrow \quad$ Fromberg Schaeffer, S (1983): The Madness of a Seduced Woman. Harmondsworth: Penguin.

-. $(M T) \rightarrow \quad$ Carter, A (1981): The Magic Toyshop. London: Virago Press.

-. $($ PPS $) \rightarrow \quad$ George, E (1999): In Pursuit of the Proper Sinner. London: Hodder and Stoughton.

-. $(R D) \rightarrow \quad$ Ishiguro, K (1989): The Remains of the Day. London: Faber and Faber.

-. $(R L) \rightarrow \quad$ Shields, C (1993): The Republic of Love. London: Flamingo.

-. (WSS) $\rightarrow \quad$ Rhys, J (1966): Wide Sargasso Sea. Harmondsworth: Penguin.

It may be the case, however, that the example is followed by a linguist's name. Whenever this happens, it means that the example under discussion has been taken from the linguist's work, whose year of publication is also pointed out.

3. It has to be pointed out, however, that this fact was originally advanced within the domains of Traditional Grammar (cf. Jespersen, 1909-49; Kruisinga, 1922; Zandvoort, 1957). In point of fact, it was Jespersen who first called 'quasi-predicatives' those constructions with both attributive and predicative features. 
4. Although Hernández Alonso's quotation explains the situation undergone by attribution in the Spanish language, it can perfectly be applied to the English linguistic situation as well. In this sense, therefore, the two 'ghostly verbs' referred to in the quotation should be interpreted as be and become, and not as the Spanish copulas ser and estar.

5. Nevertheless, the current and increasing interest in such a grammatical field is not exclusive to the Spanish and English languages. As the collection of papers on attributive and some other related issues edited by m. M. Gaulmyn and S. Remi-Giraud in 1991 demonstrates, the attributive phenomenon also enjoys a privileged and exceptional situation in the French linguistic tradition.

6. We take the term 'theme' from Gutiérrez Ordóñez (1986: 25) in order to label the nominal entity that becomes the logical subject of the attribute. It should not, therefore, be interpreted as the pragmatic term, opposed to 'rheme', referring to the clausal element that carries old information, nor as the thematic role assigned to the participant of the predication that experiences a displacement.

7. We use the \# symbol in front of sentence (34b) to indicate that the clause is grammatically acceptabie if interpreted with a non-attributive meaning. That is, as an intransitive structure with a motion verb.

8. Apart fom the aspectual variants of the copula be that, like become, grow get, go, etc., imply a change of state, Rivière (1981: 154-164) includes in this same verbal category three other groups of verbs: (a) the causative auxiliaries get, make and drive; (b) those motion verbs that denote the transition from one intial place to a final location, and (c) finally, the verb get in all its syntacticosemantic patterns.

\section{Works Cited}

Chafe, W. (1970): Mearing and the Structure of Language. Chicago: University of Chicago Press.

Curme, G. O. (1931): A Grammar of the English Language, 3. (Syntax). Boston: Heath.

Demonte, V. (1991): Detrás de la palabra. Estudios de gramática del español. Madrid: Alianza.

Downing, A. and P. Locke (1992): A University Course in English Grammar. New York: Prentice Hall.

Gaulmyn, M. M. and S. Remi-Giraud (eds.) (1991): A la Recherche de l'Attribut. Lyon: Presses

Universitaires de Lyon.

Garrudo, F. (1991, 1996): Diccionario sintáctico del verbo inglés, I y II. Barcelona: Ariel.

Givón, T. (1993): English Grammar. A Function-Based Introduction. Amsterdam: John Benjamins.

Gonzálvez García, F. (1996): Towards an understanding of the syntax-semantics relationship in complex transitive complementation in contemporary British English. Ph. D. Dissertation.

Bologna: Reale Collegio di Spagna, University of Bologna. (2 vols.)

(1998): "Complex-transitive complementation revisited: from Quirk et al.'s Grammar of Contemporary English to the international corpus of English." In M. Martínez Vázquez, ed., Transitivity Revisited. Universidad de Huelva, 95-130.

Greenbaum, S. and R. Quirk (1990): A Student's Grammar of the English Language. London: Longman.

Gutiérrez Ordóñez, S. (1986): Variaciones sobre la atribución. León: Universidad de León. Halliday, M.A.K. (1967-68) "Notes on transitivity and theme in English." Journal of Linguistics 3: 37-81; 199-244 \& Journal of Linguistics 4: 179-215. 
Hernández Alonso, C. (1971): "Atribución y predicación." Boletín de la Real Academia Española LIX: 327-340.

Jackson, H. (1990): Grammar and Meaning. A Semantic Approach to English Grammar. London: Longman.

Jespersen, O. (1909-49): A Modern English Grammar on Historical Principles, III. London: Allen \& Unwin.

Kac, M. B. (1972): "Action and Result: Two Aspects of Predication in English." Syntax and Semantics 1: 117-124.

Kruisinga, E. (1922): A Handbook of Present-Day English, II. (Accidence and Syntax). Groningen: Noordhoff, 1931 ( $5^{\text {th }}$ edition).

Levin, B. (1993): English Verb Classes and Alternations. Chicago: The University of Chicago Press.

Martínez Vázquez, M. (1991): Sintaxis inglesa: la atribución. (Estudio sintáctico-semántico de las estructuras atributivas en inglés contemporáneo). Cáceres: Universidad de Extremadura. Penadés Martínez, I. (1994): Esquemas sintáctico-semánticos de los verbos atributivos del español. Madrid: Universidad de Alcalá.

Porroche Ballesteros, M. (1990): Aspectos de la atribución en español. Zaragoza: Pórtico. Poustma, H. (1926-29): A Grammar of Late Modern English. Groningen: Noordhoff.

Rapoport, T. R. (1993): "Stage and Adjunct Predicates: Licensing and Structure in Secondary Predication Constructions." In E. Reuland y W. Abraham, eds., Knowledge and Language, II. Lexical and Conceptual Structure. Dordrecht: Kluwer Academic Press, 157-182.

Rivière, C. (1981) "Résultatifs anglais et transitivité." Modèles Linguistiques 3: 162-180.

Simpson, J. (1983): "Resultatives." In L. Levin, M. Rappaport y A Zaenen, eds., Papers in Lexical-Functional Grammar. Bloomington: Indiana Linguistics Club, 143-157.

Zandvoort, R. W. (1957): A Handbook of English Grammar. London: Longman. 